\title{
Prevalence of depressive symptoms and diagnosed depression among subjects with longstanding type 1 diabetes and no serious chronic complications, hospitalized due to inadequate metabolic control of diabetes
}

\section{ABSTRACT}

Introduction. Depressive symptoms and depressive disorders are common comorbid problems in diabetes. Type 1 diabetes is a chronic disease requiring continuous insulin treatment. A demand for performing daily self-management tasks like blood glucose checks, insulin injections, following healthy diet and maintaining regular physical activity may result in diabetes-related distress and depression. That in turn may be a barrier in achieving therapeutic goals. The aim of this study was to assess the prevalence of depressive symptoms and diagnosed depressive disorder among subjects with long duration of type 1 diabetes and no chronic complications causing disability.

Material and methods. 283 subjects (151 women), aged $43.0 \pm 10.7$ years, type 1 diabetes duration 27.2 $\pm 6.1, \mathrm{HbA}_{1 \mathrm{c}} 8.1 \pm 1.4 \%(65 \pm 8.2 \mathrm{mmol} / \mathrm{mol})$ were included. Subjects diagnosed with chronic complica-

Address for correspondence:

dr n. med. Anna Duda-Sobczak

Katedra i Klinika Chorób Wewnętrznych i Diabetologii

Uniwersytet Medyczny im. K. Marcinkowskiego

ul. Mickiewicza 2, 60-834 Poznań

Phone: +48612245270

Fax: +48 612245445

e-mail: a_sobczak@onet.pl

Clinical Diabetology 2016, 5, 6, 173-177

DOI: $10.5603 /$ DK.2016.0030

Received: 19.07.2016

Accepted: 24.02 .2017 tions causing disability were excluded to avoid the presumable impact of irreversible disability condition on questionnaire answers. Participants were asked to complete the Beck Depression Inventory (BDI) to assess the incidence and intensity of depressive symptoms. The frequency of diagnosed depression disorder was assessed based on the patients' medical history and medical charts' review.

Results. $\mathbf{4 2 . 0 \%}$ of subjects exhibited any of depressive symptoms, women two times more frequently. $10.9 \%$ of patients had been diagnosed with depressive disorder previously. Among 45 subjects with moderate or severe depressive symptoms, only 17 had been diagnosed with depressive disorder.

Conclusions. Depressive symptoms constitute a serious problem in chronic disease. The results of our study confirm the high prevalence of depressive symptoms among subjects with longstanding type 1 diabetes, although not frequently diagnosed. (Clin Diabetol 2016; 5, 6: 173-177)

Key words: type 1 diabetes, depression, depressive symptoms, Beck Depression Inventory, chronic disease

\section{Introduction}

Diabetes and depression are both chronic diseases. Moreover, the prevalence of depression among patients with diabetes, both type 1 and type 2 is higher than in general population and thought to be at least double 
[1-3]. Type 1 diabetes is a chronic disease requiring complex and demanding treatment based on insulin therapy. The treatment goals include appropriate glycated hemoglobin $\left(\mathrm{HbA}_{1 \mathrm{c}}\right)<7 \%(<53 \mathrm{mmol} / \mathrm{mol})$, low glucose variability, prevention of acute and chronic complications such as microvascular retinopathy, nephropathy, neuropathy or macrovascular myocardial infarction or stroke [4]. Since the results of The Diabetes Control and Complications Trial have been published in 1993, a need for good metabolic control in terms of prevention of chronic complications is emphasized in diabetes management guidelines [5]. An intensive functional insulin therapy has been recommended as a method of choice for well-educated patients, when a premeal insulin dose is calculated on a basis of current glucose level, amount of carbohydrate in a meal and planned physical activity. Patient is thus obliged to perform daily diabetes self-management tasks, as performing regular glucose checks, exercising, following proper diet to maintain good metabolic control. The symptoms of depression in type 1 diabetes may appear due to various causative factors. They encompass those of physiological, psychological and environmental origin. [6]. High glucose variability, with frequent episodes of hypo- and hyperglycaemia is associated with the feeling of fatigue and depressive mood [7]. Some endocrine dysregulation and elevated levels of inflammation markers observed in diabetes may also play a role $[8,9]$. Difficulties with adjusting the rules of demanding treatment to the existing lifestyle, development of chronic complications, long disease duration, inadequate family support, economic issues like unemployment and low income may as well be a source of emotional distress and depression $[10,11]$. That in turn may affect motivation for the proper treatment. The result of poorer metabolic control is manifested by elevated risk for developing chronic complications. As the need for early diagnosing and treating comorbid depression in type 1 diabetes is well established, there is still insufficient data on prevalence of depressive disorders in this group of patients. The aim of this study was to assess the prevalence of depressive symptoms and diagnosed depression among subjects with long duration of type 1 diabetes.

\section{Material and methods}

A total of 306 patients from our clinic were identified as eligible to participate in the study. All of them were admitted to the clinic due to inadequate metabolic control of diabetes. Of these, 2 refused participation because of lack of interest, 21 failed to complete baseline data. Finally, 283 subjects (151 women), among patients hospitalized in our Department were included in our study. The mean age was $43.0 \pm 10.7$ years, type 1 diabetes duration $27.2 \pm 6.1$ years, $\mathrm{HbA}_{1 \mathrm{c}}$ $8.1 \pm 1.4 \%(65 \pm 8.2 \mathrm{mmol} / \mathrm{mol})$. We excluded patients with diagnosed chronic complications causing disability, like blindness, end stage renal disease manifested by estimated glomerular filtration rate (eGFR) $<15 \mathrm{ml} /$ $/ \mathrm{min} / 1.72 \mathrm{~m}^{2}$ (eGFR was calculated using Modification of Diet in Renal Disease (MDRD) study equation), painful peripheral neuropathy or history of limb amputation, to avoid the presumable impact of irreversible disability condition on questionnaire answers. Participants were asked to complete the Beck Depression Inventory (BDI) to assess the incidence and intensity of depressive symptoms. BDI is a 21-question self-report tool used for screening for symptoms of depression, designed for individuals over the age of 13 years. It comprises the period of the last seven days and the items included relate to the emotional symptoms of depression like irritability, hopelessness, self-dislike as well as the somatic symptoms such as weight loss, insomnia or fatigue. Participants were then divided into four subgroups based on the inventory's standard cut-offs, according to gained scores. The frequency of previously diagnosed depression was based on the interview and the review of patients' medical records. We assumed that the patient was diagnosed with depression if the medical chart confirmed recurrent major depressive disorder, F33 according to the ICD-10, International Statistical Classification of Diseases and Related Health Problems, irrespective of currently implemented treatment and the diagnosis was determined by a psychiatrist. During hospitalization participants had taken blood samples to perform laboratory test. The glycemic control was expressed by measuring $\mathrm{HbA}_{1 \mathrm{c}}$ with the use of high-performance liquid chromatography (HPLC). Body mass index (BMI) was calculated among all participants. We assessed the presence of diabetic chronic complications. Diabetic retinopathy was diagnosed using direct ophthalmoscopy through dilated pupils by ophthalmologist. Diabetic nephropathy was detected via measurement of albumin-to-creatinine ratio and at the estimated glomerular filtration rate (eGFR). Peripheral neuropathy assessment was performed using pressure sensation (10 g monofilament perception), vibration perception (128- $\mathrm{Hz}$ tuning fork) and ankle reflex tests. Diabetic neuropathy was diagnosed in patients with two or more of the following four components: the presence of typical symptoms of neuropathy, the absence of ankle tendon reflexes, and/or abnormal scores for pressure and/or vibration perception. The characteristics of studied group are shown in Table 1.

Statistical analysis was performed using Statistica PL version 10.0 (StatSoft Inc., Tulsa, USA). The results of continuous variables are shown as means \pm SD for 
Table 1. The characteristics of studied group, $n=283$

\begin{tabular}{lc}
\hline Age, years & $43.0 \pm 10.7$ \\
Sex (M/F) & $132 / 151$ \\
Diabetes duration (years) & $27.2 \pm 6.1$ \\
$\mathrm{HbA}_{1 \mathrm{c}}(\%)$ & $8.1 \pm 1.4$ \\
$\mathrm{HbA}_{1 \mathrm{c}}[\mathrm{mmol} / \mathrm{mol}]$ & $65 \pm 8.2$ \\
Body mass index - BMI $\left[\mathrm{kg} / \mathrm{m}^{2}\right]$ & $25.3 \pm 3.8$ \\
Retinopathy, $\mathrm{n}(\%)$ & $217(76.7)$ \\
Neuropathy, $\mathrm{n}(\%)$ & $116(41.0)$ \\
Nephropathy, $\mathrm{n}(\%)$ & $60(21.2)$ \\
\hline
\end{tabular}

Data are presented as means \pm standard deviation or number and percentage

normally distributed data or as number and percentage of patients for categorical data. The Kolmogorov-Smirnov test with Lilliefors correction was used to test for normality. The analysis of variance (ANOVA) with the Levene's test were used to evaluate differences in $\mathrm{HbA}_{1 \mathrm{c}}$ between particular BDI groups. A p-value lower than 0.05 was accepted as statistically significant.

The study was conducted in accordance with the Declaration of Helsinki and the protocol was approved by the local Ethics Committee (decision No. 346/2010). All participants were adults and provided written informed consent after reading a description of the study.

\section{Results}

The mean BDI score in the study group was 8 (IQR 4-14) points. 31 participants (10.9\%) had been previously diagnosed with depressive disorder. According to $\mathrm{BDI}, 42.0 \%$ presented any of depressive symptoms, women more frequently. Among 45 subjects with moderate or severe depressive symptoms as indicated in BDI, only 17 had been previously diagnosed with depressive disorder. The results are shown in Table 2. We analyzed the metabolic control of diabetes in four patient subgroups according to exhibited BDI score. The mean percentage of $\mathrm{HbA}_{1 c}$ was higher among patients of higher BDI group, although the difference was not significant ( $p=0.7$; Tab. 3). There was no significant
Table 3. The differences in $\mathrm{HbA}_{1 c}$ between $\mathrm{BDI}$ groups. Analysis of variance (ANOVA)

\begin{tabular}{|c|c|c|}
\hline $\begin{array}{l}\text { Beck Depression Inventory } \\
\text { (BDI) score }\end{array}$ & $\begin{array}{c}\mathrm{HbA}_{1 \mathrm{c}} \pm \mathrm{SD} \\
(\%)\end{array}$ & P-value \\
\hline 0-9 (minimal or no depression) & $8.0 \pm 1.3$ & 0.7 \\
\hline 10-18 (mild depression) & $8.1 \pm 1.6$ & \\
\hline 19-29 (moderate depression) & $8.1 \pm 1.4$ & \\
\hline$>30$ (severe depression) & $8.5 \pm 1.5$ & \\
\hline
\end{tabular}

Data are presented as means \pm standard deviation (SD)

difference regarding $\mathrm{HbA}_{1 \mathrm{c}}$ between patients with no or mild depression and severe depression $(p=0.3$; Student t-test). Also bivariate correlation indicated no significant association between $\mathrm{BDI}$ scores and $\mathrm{HbA}_{1 \mathrm{c}}$ $(r=0.76 ; p=0.2)$.

\section{Discussion}

The prevalence of major depressive episodes for lifetime in general population varies widely, according to demographic differences, with the majority in the range of $8 \%$ to $12 \%$ [12]. The prevalence of depression in comorbid type 1 diabetes is even several fold higher and usually ranges between $11 \%$ and $30 \%$ [13]. Depressive symptoms in type 1 diabetes may be of physiological, psychological and environmental origin. Rapid fluctuations of glucose levels, chronic hyperglycemia, acute hypo or hyperglycemia are associated with low grade inflammation, elevated cytokine levels and oxidative stress [14]. High variability of glucose levels may influence the function of brain areas responsible for mood and cognition and therefore precipitate depressive symptoms [15]. To emphasize, in our study, none of participants had symptoms of hypoglycemia or acute hyperglycemia during answering the questionnaire. Moreover, depressive symptoms may be perceived as the reaction for the diagnosis of the chronic disease and the demanding treatment of diabetes requiring implementation of many lifestyle modifications [16]. In our study, the percentage of patients with previously diagnosed depressive disorder was lower than expected and

Table 2. Prevalence of depressive symptoms and diagnosed depressive disorder in studied group, $\mathrm{n}=283, \mathrm{n}$ (female)

\begin{tabular}{lccc}
\hline $\begin{array}{l}\text { Beck Depression Inventory } \\
\text { (BDI) score }\end{array}$ & $\begin{array}{c}\text { Subjects with no previously } \\
\text { diagnosed depressive disorder, } \\
\mathbf{n = 2 5 2}(\mathbf{1 3 0} \text { female) }\end{array}$ & $\begin{array}{c}\text { Subjects with previously } \\
\text { diagnosed depressive disorder, } \\
\mathbf{n = 3 1}(\mathbf{2 1} \text { female) }\end{array}$ & $\begin{array}{c}\text { Female } \\
(\%)\end{array}$ \\
\hline $0-9$ (minimal or no depression) & $157(67)$ & $7(4)$ & 43.3 \\
$10-18$ (mild depression) & $67(47)$ & $7(5)$ & 70.3 \\
$19-29$ (moderate depression) & $23(12)$ & $6(4)$ & 58.8 \\
$>30$ (severe depression) & $5(4)$ & 72.7 \\
\hline
\end{tabular}


similar to general population. One explanation might be the fact of underdiagnosing depression among type 1 diabetes patients. According to the Pathways Study, about $49 \%$ of patients with major depression and diabetes were unrecognized by the primary health care system [17]. This observation is consistent with the study by $\mathrm{Li}$ et al. that showed $45 \%$ of adult diabetes patients with undiagnosed depression (either major or minor) [18]. Thereby it is important to underline the role of psychological or psychiatric consultation in our patients. When therapeutic goals for individuals with diabetes are depicted, a multidisciplinary approach should be performed by a therapeutic team including i.e. diabetologist, psychologist or dietitian. Once diagnosed and treated, the symptoms of depression alleviate. In our study, almost half of patients with diagnosed depression presented none or mild depressive symptoms according to BDI. This effect might be associated with proper psychiatric and psychological care.

When analyzing scores gained in BDI, approximately $40 \%$ of participants presented any of depressive symptoms. This remains consistent with previous studies [19]. However, we must note that subjects with disabling complications were excluded and thus the actual percentage of participants presenting with depressive symptoms might be higher. The prevalence of depressive symptoms was about two-fold higher in women than men. This observation has been widely described in literature. The explanation is complex and involves psychological, environmental and neuroendocrinological factors [20, 21].

The comorbidity of depression in people with diabetes is associated with poor metabolic control and higher complication rates [3]. Although the mean percentage of $\mathrm{HbA}_{1 \mathrm{c}}$ was higher among patients of higher BDI group in our study, the difference was not significant. One explanation may be the fact, that the group of subjects with severe depression was too small to reach statistical significance. Again, another explanation, that the study group was carefully selected and patients with serious complications were excluded.

The limitation of our study is the assessment of depressive symptoms based on self-report questionnaire which is considered less precise and overestimating the prevalence of symptoms [19]. Many environmental and personal factors can have an impact on the final score of BDI. Completing the inventory out in the clinic, in front of the doctor compared to doing it individually in home is only one example. Moreover, BDI is still a screening tool for depressive symptoms and cannot be used for diagnosing depressive disorders. The diagnostic psychiatric interview, although more time consum- ing allows for an accurate diagnosis. Nevertheless Beck Depression Inventory may be a useful tool for screening purposes and some advanced diagnostic steps may be taken subsequently as needed.

\section{Conclusions}

The results of our study confirm the high prevalence of depressive symptoms among subjects with longstanding type 1 diabetes. More studies are needed to assess the actual frequency of depressive disorder in type 1 diabetes based on the previous screening with the use of BDI.

\section{REFERENCES}

1. Gendelman N, Snell-Bergeon JK, McFann K et al. Prevalence and correlates of depression in individuals with and without type 1 diabetes. Diabetes Care 2009; 32: 575-579.

2. Ali S, Stone MA, Peters JL et al. The prevalence of co-morbid depression in adults with Type 2 diabetes: a systematic review and meta-analysis. Diabet Med 2006; 23: 1165-1173.

3. Egede L, Ellis C. Diabetes and depression: Global perspectives. Diab Res Clin Pract 2010; 87: 302-312.

4. American Diabetes Association. Standards of medical care in diabetes - 2016. Diabetes Care 2016; 39 (Suppl 1).

5. The Diabetes Control and Complications Trial Research Group. The effect of intensive treatment of diabetes on the development and progression of long-term complications in insulin-dependent diabetes mellitus. N Engl J Med 1993; 329: 977-986.

6. Dziemidok P, Makara-Studzińska M, Jarosz MJ. Diabetes and depression: a combination of civilization and life-style diseases is more than simple problem adding - literature review. Ann Agric Environ Med 2011; 18: 318-322.

7. Warren RE, Deary IJ, Frier BM. The symptoms of hyperglycaemia in people with insulin-treated diabetes: classification using principal components analysis. Diabetes Metab Res Rev 2003; 19: $408-414$

8. Chan O, Inouye K, Riddell MC et al. Diabetes and the hypothalamo-pituitary-adrenal (HPA) axis. Minerva Endocrinol 2003; 28: 87-102.

9. Raison CL, Capuron L, Miller AH. Cytokines sing the blues: inflammation and the pathogenesis of depression. Trends Immunol 2006; 27: 24-31.

10. Collins MM, Corcoran P, Perry IJ. Anxiety and depression symptoms in patients with diabetes. Diabet Med 2009; 26: 153-161.

11. Polonsky WH, Anderson BJ, Lohrer PA et al. Assessment of diabetes-related distress. Diabetes Care 1995; 18: 754-760.

12. Andrade L, Caraveo-Anduaga JJ, Berglund $\mathrm{P}$ et al. The epidemiology of major depressive episodes: results from the International Consortium of Psychiatric Epidemiology (ICPE) Surveys. Int Methods Psychiatr Res 2003; 12: 3-21.

13. Pouwer F, Geelhoed-Duijvestijn PH, Tack CJ et al. Prevalence of comorbid depression is high in out-patients with Type 1 or Type 2 diabetes mellitus. Results from three out-patient clinics in the Netherlands. Diabet Med 2010; 27: 217-224.

14. Champaneri S, Wand GS, Malhotra SS, Casagrande SS, Golden $\mathrm{SH}$. Biological basis of depression in adults with diabetes. Curr Diab Rep. 2010; 10: 396-405.

15. Lyoo IK, Yoon SJ, Musen G et al. Altered prefrontal glutamateglutamine-gamma-aminobutyric acid levels and relation to low cognitive performance and depressive symptoms in type 1 diabetes mellitus. Arch Gen Psychiatry 2009; 66: 878-887. 
16. Holt RI, de Groot M, Golden SH. Diabetes and depression. Curr Diab Rep 2014; 14: 491

17. Katon WJ, Simon G, Russo Jet al. Quality of depression care in a population-based sample of patients with diabetes and major depression. Med Care 2004; 42: 1222-1229.

18. Li C, Ford ES, Zhao G, Ahluwalia IB, Pearson WS, Mokdad AH. Prevalence and correlates of undiagnosed depression among U.S. adults with diabetes: the Behavioral Risk Factor Surveillance System, 2006. Diabetes Res Clin Pract 2009; 83: 268-279.
19. Barnard KD, Skinner TC, Peveler R. The prevalence of co-morbid depression in adults with Type 1 diabetes: systematic literature review. Diabet Med 2006; 23: 445-448.

20. Oquendo MA, Turret J, Grunebaum MF et al. Sex differences in clinical predictors of depression: A prospective study. J Affect Disord 2013; 150: 1179-1183.

21. Naninck EF, Lucassen PJ, Bakker J. Sex differences in adolescent depression: do sex hormones determine vulnerability? J Neuroendocrinol 2011; 23: 383-392. 